\title{
Resenha de "Língua como linha de força do dispositivo colonial: os Gavião entre a aldeia e a universidade"
}

A Review of "Language as a force line of the colonial device: the Gavião between the village and the university"

Marcus Vinícius Da Silva ${ }^{1}$

Colégio de Aplicação da Universidade Federal de Roraima - UFRR

marcus.silva@ufrr.br

LISBÔA, Flávia Marinho. Língua como linha de força do dispositivo colonial: os Gavião entre a aldeia e a universidade. 2019. 276f. Tese (Doutorado) Programa de Pós-Graduação em Letras, Instituto de Letras e Comunicação, Universidade Federal do Pará, Belém, 2019.

\footnotetext{
${ }^{1}$ Mestre em Letras Neolatinas (Estudos Linguísticos de Língua Espanhola) pelo Programa de Pós-Graduação em Letras Neolatinas da Universidade Federal do Rio de Janeiro (UFRJ); Doutorando em Linguística e Língua Portuguesa pelo Programa de Pós-Graduação em Linguística e Língua Portuguesa da Universidade Estadual Paulista "Júlio de Mesquita Filho" (UNESP-Araraquara); Professor do Colégio de Aplicação da Universidade Federal de Roraima (CAp/UFRR) Boa Vista RR. Lattes: <http://lattes.cnpq.br/5513601185586347>. ORCID: http://orcid.org/0000-0003-3907-3277.
} 
Marcus Vinícius Da Silva. Resenha de "Língua como linha de força do dispositivo colonial: os Gavião entre a aldeia e a universidade".

No Brasil, não é tão comum e habitual encontrar nos periódicos acadêmicos da área de Letras/Linguística resenhas de dissertações e de teses. No entanto, em outros países, é comum encontrar resenhas de boas dissertações e teses (TESCARI NETO, 2019, p. 107). A Tese de Flávia Marinho Lisbôa se encaixa nessa discussão a respeito de boas teses produzidas - foi inclusive indicada ao Prêmio CAPES de Teses 2020 -, na medida em que apresenta importantes discussões e reflexões, do ponto de vista dos estudos discursivos foucaultianos, em diálogo com uma perspectiva decolonial, sobre o papel da língua nas práticas sociodiscursivas da Universidade Federal do Sul e Sudeste do Pará (Unifesspa), principalmente no que toca a permanência de alunos indígenas Gavião dos grupos Parkatejê, Akrãtikatejê e Kyikatjê na instituição.

A tese intitulada Língua como linha de força do dispositivo colonial: os Gavião entre a aldeia e a universidade foi desenvolvida no Programa de Pós-Graduação em Letras, no Instituto de Letras e Comunicação, da Universidade Federal do Pará (UFPA), tendo como orientadora a Profa. Dra. Ivânia dos Santos Neves. O trabalho é composto por quatro partes, dividas em torno de sete capítulos, versando sobre aspectos teóricos e analíticos, a saber a distribuição de capítulos: (i) Entre a Etnografia e a Análise do Discurso: desafios epistemológicos; (ii) Decolonialidades, Genealogias e Dispositivo; (iii) Universidade e a Convergência Indígena; (iv) Subjetividades que interpelam a Unifesspa: conquistas, dificuldades e desafios; (v) Cosmologias fraturadas Timbira-Gavião; (vi) Subjetividades que marcam as diferenças do aluno indígena gavião e; (vii) Universidade e Linguagens: língua como linha de força do dispositivo colonial.

O referencial teórico-metodológico da investigação filia-se à perspectiva da Análise do Discurso com Michel Foucault - reivindicada, no Brasil, sobretudo a partir dos trabalhos de Maria Rosário Gregolin -, em diálogo com a perspectiva de estudos Decoloniais. A pesquisa tem como objetivo geral evidenciar o papel da língua/linguagem nas práticas sociodiscursivas da universidade, como instituição de materialização e que materializa as normatividades hegemônicas do dispositivo colonial, para a permanência de alunos indígenas na instituição.

De acordo com Lisbôa (2019), os direitos dos povos indígenas são frequentemente atacados em diferentes discursos e instâncias, inclusive, ataques que têm como pano de fundo a retirada dos direitos elementares, tais como o direito à existência e o direito ao território. De igual modo, a autora nos alerta que outros direitos também têm sido cerceados, principalmente aqueles relacionados às cotas e à garantia de vagas específicas nas universidades. É nessa perspectiva de direito e luta dos povos indígenas que se inscreve a 
Marcus Vinícius Da Silva. Resenha de "Língua como linha de força do dispositivo colonial: os Gavião entre a aldeia e a universidade".

Tese de Flávia Marinho Lisbôa, na medida em que visibiliza a luta dos povos indígenas para diminuição das desigualdades historicamente construídas.

No primeiro capítulo "Entre a Etnografia e a Análise do Discurso: desafios epistemológicos", a autora nos elucida sobre os seus fraturados lugares de fala da/na pesquisa e explica a contribuição da pesquisa de campo para as suas reflexões teórico-metodológicas, visto que a experiência etnográfica possibilitou o entendimento do que é ser aluno indígena na universidade (LISBÔA, 2019, p. 38), além de contribuir para desconsiderar a concepção do aluno indígena como qualquer outro aluno não indígena. De acordo com a pesquisadora, a inscrição nessa perspectiva etnográfica possibilitou compreender ainda outras formas o ser indígena.

\begin{abstract}
Mesmo como alguém sensível às causas dos povos indígenas, ainda era atravessada por pensamentos homogeneizantes como reflexo do dispositivo colonial, e a vivência de campo serviu para interpelar meu olhar de pesquisadora, evidenciando a experiência do campo como de extrema importância para desmistificar ainda mais os discursos colonizadores acerca do indígena (LISBÔA, 2019, p. 38).
\end{abstract}

Diante de uma atitude genealógica de pesquisa, Lisbôa (2019) nos esclarece que habitualmente e tradicionalmente a Análise do Discurso tem como foco analítico a análise de materializações que circulam em diferentes formas e meios de comunicação (2019, p. 39). Entretanto, ela explicita que para sua proposta de pesquisa foi necessário ouvir os próprios alunos e suas subjetividades a respeito da sua permanência na universidade. Nesse sentido, a autora nos aclara que a etnografia é um significativo mecanismo para suas discussões e reflexões, uma vez que é importante a percepção e pensamento para a construção do conhecimento (OLIVEIRA, 1996, apud LISBÔA, 2019).

Para a realização da pesquisa de campo, em uma perspectiva etnográfica, a pesquisadora informa que foram realizadas nove visitas às aldeias Gavião Parkatêjê, Akrãtikatêjê e Kyikatêjê, entre o período de 2017 a 2018, com intuito de investigar quais são as dificuldades enfrentadas pelos alunos Gavião no que concerne ao acesso e à permanência na universidade. Para o seu desenvolvimento, Lisbôa (2019) nos pontua que foi necessário recorrer a um corte temporal, de 2010 a 2016, para compreender o processo de acesso dos indígenas na Unifesspa, o que evidenciou que, dos 96 indígenas ingressantes, 52 eram da etnia Gavião, o que contribuiu para o desenvolvimento da pesquisa.

No segundo capítulo, "Decolonialidades, Genealogias e Dispositivo", a pesquisadora dá prosseguimento à reflexão teórica da sua pesquisa, esclarecendo-nos que assume, como mencionado no capítulo anterior, uma perspectiva de fratura teórica, no sentido de incorporar 
Marcus Vinícius Da Silva. Resenha de "Língua como linha de força do dispositivo colonial: os Gavião entre a aldeia e a universidade".

aos estudos sobre decolonialidade as reflexões do conceito de dispositivo teorizadas por Foucault no âmbito da Análise do Discurso. Para tanto, Lisbôa (2019) resgata a memória discursiva das discussões que comparecem nas teorizações de Foucault, diferenciando as propostas de arqueologia, genealogia e arquegenealogia dentro dos escopos epistemológicos da Análise do Discurso.

Para Lisbôa (2019), existem muitos entraves quando se postula a palavra "método" nos estudos discursivos foucaultianos:

Há muitos perigos ao se falar de "método" envolvendo um autor como Michel Foucault, cuja reflexão tem como marca preponderante a de evidenciar os contrassensos no estabelecimento de muros, barreiras em torno da construção do conhecimento científico. Logo, é preciso localizar a concepção de método empregada aqui, evidenciando, então, a forma como os enunciados são tratados nesta pesquisa, seguindo os preceitos foucaultianos na compreensão do discursivo e sua estreita relação com os demais acontecimentos sociais, chamando-nos a atenção para o papal da linguagem, do discurso, nas/pelas lutas sociais, o que então o "método arquegenealógico" nos permite fazer (LISBÔA, 2019, p. 66-67).

Em um segundo momento, a autora, para evidenciar a produtividade teórica existente entre as linhas de pesquisa - Análise do Discurso com Michel Foucault e Estudos Decoloniais -, reflete discursivamente sobre pêndulo da presença/ausência indígena na universidade na atualidade em relação com o percurso histórico (LISBÔA, 2019, p. 66). Cabe mencionar, ainda, que é neste capítulo, que são discutidos os pontos basilares dessa (inter)relação teórica proposta, além do aprofundamento da discussão a respeito do conceito de dispositivo foucaultiano.

No terceiro capítulo "Universidade e a Convergência Indígena", há uma importante e necessária reflexão sobre o papel da universidade para construção das subjetividades. No entanto, a Lisbôa nos provoca dizendo que é preciso pensar a universidade de forma heterogênea, tendo em vista que ela foi se constituindo e se materializando ao longo do tempo ao redor do mundo, em diferentes espaços e tempos, inclusive com políticas ideológicas muito distintas (SANTOS; FILHO, 2008, apud LISBÔA, 2019).

De igual modo, a analista nos relembra que, na América, a constituição e a implementação dos modelos de universidade se deram de forma tardia, em virtude dos processos de colonização, além de estarem enraizadas às concepções hegemônicas de ensino, no sentido de pensamentos decorrentes de uma perspectiva de política colonial, a qual cerceava o direito de abertura de cursos de ensino superior em países colonizados, a exemplo 
Marcus Vinícius Da Silva. Resenha de "Língua como linha de força do dispositivo colonial: os Gavião entre a aldeia e a universidade".

do o Brasil, que foi colônia de Portugal. É importante mencionar que essa mudança de perspectiva colonial apenas se deu com a vinda da Família Real para o Brasil.

O que levou à mudança de pensamento sobre a autorização para implantar o Ensino Superior no Brasil foi a vinda da família real em 1808, motivando alterações profundas nas condições institucionais da primeira colônia portuguesa da América do Sul, lembrando que Portugal tinha duas colônias na América: a província do Brasil e a província do Grão-Pará e Maranhão. Nessa condição de sede do império, D. João VI precisou promover uma série de reformas na dinâmica social local e, entre outras medidas, criou as duas primeiras faculdades de medicina no país (LISBÔA, 2019, p. 96-97).

A respeito dessa mudança de perspectiva colonial de implementação de cursos de nível superior no Brasil, a pesquisadora traz à baila que, mesmo com essa aparentemente mudança de política educacional, apenas as classes dominantes/elitizadas adentravam esse espaço formativo da universidade, com o objetivo de acessar o capital simbólico e cultural (BOURDIER, 2011), visto que continuariam mantendo os marcadores de classes sociais e grupos privilegiados do restante da população, o que configurava a universidade como um espaço de desigualdade social, no sentido de reforçar uma política homogênea de acesso e de permanência.

No quarto capítulo, "Subjetividades que interpelam a Unifesspa: conquistas, dificuldades e desafios", Lisbôa (2019) esclarece, do ponto de vista histórico, que a educação formal para os povos indígenas começou a ser implementada desde o início do processo de colonização por meio do processo de catequização imposto pela Igreja Católica. Souza (2016) argumenta que, somente depois de muito tempo, as ações educacionais para os povos indígenas passaram a ser lideradas por instituições tutelares do Estado, tais como SPI e Funai, as quais eram responsáveis por essas ações durante a Ditadura Militar.

Tratava-se de uma educação colonizadora, arrogante, nem mesmo com algum tipo de dosificação do uso da língua na sala de aula. Ministradas em português, as aulas seguiam um modelo de ensino que era o mesmo das grandes cidades brasileiras. $\mathrm{Na}$ verdade o currículo era aquele do sul do país, com exemplos que nada tinham a ver com a realidade das crianças indígenas. As mesmas matérias, os mesmos livros didáticos, a intromissão de conceitos etnocentristas e preconceituosos nas aulas de "moral e cívica". O objetivo dessa "escola" era converter o índio, destribalizá-lo, torna-lo um zumbi espiritual. Tal escola, onde chegou a funcionar, era uma fábrica macabra de caricatura de "civilizados" (SOUZA, 2016, p. 83 apud LISBÔA, 2019, p. 121).

Apesar dessa repressão dada aos povos indígenas e ao ensino, eles começaram a lutar e a reivindicar seus direitos e, após dezoito anos de constantes batalhas, conseguem alcançar a 
Marcus Vinícius Da Silva. Resenha de "Língua como linha de força do dispositivo colonial: os Gavião entre a aldeia e a universidade".

formação em nível superior por meio da formação de professores indígenas (LISBÔA, 2019) e, consequentemente, mais tarde, conseguem adentrar em outras áreas do conhecimento dentro da universidade, com a instauração de políticas públicas de reservas de cotas e vagas para os povos indígenas nas instituições públicas de ensino.

No entanto, a autora argumenta que, infelizmente, mesmo com a implementação dessas políticas, as universidades ainda não mantêm uma postura diferenciada em suas políticas internas para esses povos, no sentido de viabilizar subsídios para permanência dos povos indígenas nas instituições. Nesse sentido, ela mostra ainda que essa problemática não é só um problema educacional, mas social, cultural, político e, até mesmo, de concepção epistemológica de entendimento do mundo e de suas relações (2019, p.130). Segundo Lisbôa (2019, p. 133), no âmbito educacional da Unifesspa:

a "linha de subjetividade" do dispositivo oscila quando começam a se estabelecer políticas públicas (por meio da Lei Federal n ${ }^{\circ} 12.711$, de 29 de agosto de 2012, e da Resolução $\mathrm{N}^{\circ}$. 3.689/2009), mas principalmente por meio de como a presença dos sujeitos beneficiados por essas políticas passam a provocar reações de dentro da estrutura acadêmica. Inseridos nessa nova configuração sociohistórica promovem as várias formas de fuga, provocam desestabilidades, dando condições de possibilidades históricas para que mudanças maiores aconteçam, para instaurar o novo. Dessa forma é que a análise do dispositivo foucaultiano pode nos orientar sobre o futuro a partir do que somos nós hoje, como resultado dos processos de resistência entendida pelo autor como "o papel de adversário, de alvo... que permite a preensão".

No quinto capítulo, "Cosmologias fraturadas Timbira-Gavião", é apresentado aos leitores os fraturados lugares de constituição do povo Gavião, constituídos de três etnias Timbira: os Parkatejê, os Kyikatejê e os Akrãtikatejê. Nesse sentido, os Timbiras, no início do século XX, dividiram-se nesses três grupos e ocuparam o território do Maranhão e a região do estado do Pará. De acordo com Lisbôa (2019), esses povos passaram por intensos processos de aniquilação ao longo dos anos, gerados, principalmente, por aspectos relacionados à exploração econômica das terras ocupadas, tais como: extração de castanha, construção da hidrelétrica de Tucuruí, abertura das grandes rodovias no estado do Pará, entre outros fatores.

Em se tratando de cosmologia do povo Gavião, é importante considerar as fraturas históricas e culturais pelas quais os indígenas atravessaram ao longo do século XX (LISBÔA, 2019, p. 70). Nesse aspecto, o povo Gavião é composto por diferentes práticas culturais:

que envolvem histórias, canções relacionadas ao cotidiano, religiosidade, rituais de diferentes ordens, isto é, a forma de expressar a compreensão sobre o mundo. Entre as complexas expressões dessa sociedade Timbira, destaca-se a narrativa Pyt me 
Marcus Vinícius Da Silva. Resenha de "Língua como linha de força do dispositivo colonial: os Gavião entre a aldeia e a universidade".

Kaxêr, O Sol e a Lua, a história sobre o começo, a criação dos primeiros homens. Para eles, o Sol, que representa a sabedoria, e a Lua, mais atrapalhado, afoito e traiçoeiro, são os criadores do mundo. A história foi narrada por Krohokrenhum e publicada no livro "Conhecendo o nosso povo" (1997), obra coordenada pela professora Leopoldina Araújo. A história aparece no livro tanto na língua dos Gavião, quanto em português [...] (LISBÔA, 2019, p. 170).

Para Lisbôa (2019), essas narrativas dos povos Gavião fazem parte da história cultural da sociedade Timbira. Apesar das narrativas possuírem diferenças, há com muita recorrência constitutivas fundamentais das duas metades cerimoniais características dos Jê na América do Sul. Nessa perspectiva, a autora traz para a tese essas narrativas escritas em torno das histórias do Sol e da Lua, visto que elas se constituem e são passadas de geração em geração por meio da oralidade, o que visibiliza a cosmologia dessa sociedade bem como a forma de explicação da humanidade. Cabe mencionar, ainda, segundo Neves (2015), que os povos indígenas foram constantemente silenciados ao longo do tempo:

As políticas públicas em relação às sociedades indígenas, desde o início do período colonial, estiveram bastante comprometidas com regimes de exploração e violência, organizadas a partir de diferentes estratégias, que procuraram interferir e silenciar as práticas culturais destes povos. Se a princípio estas iniciativas eram ditadas pelos interesses da coroa portuguesa, o Império e a República do Brasil, sem muita hesitação, em nome do desenvolvimento e da integração do país, deram prosseguimento a este sistema (NEVES, 2015, p. 21 apud LISBÔA, 2019, p. 180).

Portanto, a história entre os povos indígenas e o Estado brasileiro, infelizmente, é marcada por conflitos de diferentes naturezas, inclusive, que acontecem desde 1500 com o processo de colonização portuguesa. De acordo com a Lisbôa (2019, p. 181), “o governo brasileiro é o inimigo que conquistou o território por meio de uma guerra e a mantém por meio de leis e políticas nada eficazes voltadas para o povo derrotado, os indígenas".

O sexto capítulo da tese é intitulado "Subjetividades que marcam as diferenças do aluno indígena gavião" e tem como objetivo analisar a emergência das subjetividades relacionadas aos alunos indígenas no que concerne os efeitos de vivência na universidade, visto que é perceptível com o comparecimento e o atravessamento de marcas que os tornam diferentes dos demais alunos da instituição. De acordo com a autora, a memória da história do povo Gavião visibilizou a luta e a resistência desse povo na busca por melhoria e por direitos, tais como a educação superior e o direito à terra.

Outrossim, a pesquisadora nos recorda que a cosmologia do povo gavião foi atravessada e constituída de fraturas, em virtude da marca colonial (MIGNOLO, 2003), uma vez que "trata-se de sociedades imersas em uma estrutura social regida pela lógica da 
Marcus Vinícius Da Silva. Resenha de "Língua como linha de força do dispositivo colonial: os Gavião entre a aldeia e a universidade".

colonialidade, em que se configuram diretamente como a outridade do colonizador" (LISBÔA, 2019, p. 203). É nesse sexto capítulo que a autora dá prosseguindo ao desenvolvimento da história do povo Gavião, focando, nesse momento, nas novas condições históricas que contribuem para sua identidade atual.

Sendo assim, Lisbôa nos apresenta os enunciados que mostram diferenças cosmológicas distintas do povo Gavião, o que revela a visão do mundo hoje desses novos sujeitos indígenas, entretanto, também evidenciam alguns fatores que precisam ser refletidos e discutidos no que tange o atendimento desses sujeitos na universidade, no sentido de viabilização e de amadurecimento de políticas públicas de acesso e permanência na educação superior. Para Lisbôa, as maiores dificuldades apresentadas estão relacionadas aos fatores materiais impostos pelo neoliberalismo.

As condições materiais são os primeiros determinantes na presença dos alunos indígenas nas universidades, já que sem elas não há como participarem do cotidiano da universidade. Neste grupo, relacionamos as dificuldades com o espaço da universidade, que não é só físico, mas também virtual, necessitando permanentemente de acesso à internet; e, por fim, o transporte (2019, p. 204).

De acordo com a autora, é perceptível nos enunciados dos sujeitos indígenas entrevistados, de diferentes cursos, “[...] os estranhamentos do encontro entre indígenas e universidade, especialmente pela dificuldade da universidade para recebê-los" (LISBÔA, 2019, p. 205), o que traz à baila os resultados negativos na permanência desses sujeitos na universidade, visto que não conseguem acompanhar o ensino acadêmico e muitos acabam desistindo do ensino superior. Outras regularidades discursivas recorrentes nas entrevistas foram a falta de prática de vivência fora da aldeia e, consequentemente, dificuldades geradas pela não familiaridade com os gêneros acadêmicos cobrados nas aulas.

Além disso, a teórica argumenta que um fator que compareceu em todos os enunciados dos sujeitos indígenas do povo Gavião foi o aspecto relacionado à tecnologia, principalmente, à questão da internet, como um dos empecilhos enfrentados pelos indígenas no que toca à comunicação, tendo em vista a realidade dos municípios do interior da Amazônia - inclusive das próprias instituições federais de ensino - que, muita vezes, não oferecem suporte tecnológico e logístico para seus discentes; além disso, notam-se aspectos referentes ao racismo institucional por parte dos não indígenas e, em especial, a questão do transporte para a permanência na instituição.

Por fim, no sétimo capítulo, "Universidade e Linguagens: língua como linha de força do dispositivo colonial", a autora remonta as discussões anteriores sobre o dispositivo na 
Marcus Vinícius Da Silva. Resenha de "Língua como linha de força do dispositivo colonial: os Gavião entre a aldeia e a universidade".

perspectiva foucaultiana, em diálogo decolonial, no sentido de traçar o mesmo elo realizado por Foucault sobre a relação entre sujeito, discurso e história. A partir da análise dos enunciados dos sujeitos indígenas na Unifesspa, das práticas discursivas e das diferentes materialidades apresentadas, segundo Lisbôa (2019, p. 232) "ficou visível para nós a força imperante que atravessa de forma significativa e decisiva para a vivência acadêmica desses alunos, assim como seu acesso e permanência na universidade: a linguagem”.

Como mostra a pesquisadora, as rodas de conversas com os indígenas do povo Gavião, na perspectiva etnográfica de pesquisa, possibilitou evidenciar nas análises 8 (oito) regularidades discursivas nos enunciados, tais como: "acesso e permanência, monitoria, desconhecimento e a importância da ERER, local de referência, autoculpabilização capacitativa dos alunos, transporte, comunicação-internet, e o racismo manifesto nos seminários” (LISBÔA, 2019, p. 232). Nessa linha de pensamento, a autora (2019, p. 232-233) complementa expondo que:

Essas seriam então as evidências das oscilações nas relações de poder do dispositivo, em permanente preensão a partir da entrada de alunos indígenas na Unifesspa em função das políticas afirmativas da história recente no nosso país. Porém, nessas regularidades fica evidente que os ganhos conquistados são ganhos limitados, que não conferem em sua plenitude a emancipação dos alunos indígenas no espaço acadêmico, de forma a poderem cursar com êxito as disciplinas até chegarem ao fim da formação. Entendemos que essas demandas pontuais se manifestam na falta de uma preparação desses calouros para lidarem com o ambiente acadêmico, ambientação essa que requer conhecimentos de informática, do funcionamento burocrático e da 233 linguagem acadêmico-científica que se manifesta nos gêneros acadêmicos nunca antes vivenciados por eles [...].

A partir dessas reflexões, portanto, é perceptível que a língua(gem) atravessa todos os domínios e instâncias da produção de saberes e poderes, no sentido de ser uma grande linha de forma do dispositivo colonial e que impacta o acesso e a permanência dos alunos indígenas do povo Gavião na educação superior. Segundo Lisbôa (2019), as 8 (oito) dificuldades apresentadas pelos indígenas evidenciam que a base da convergência das problemáticas está relacionada, sobretudo, pelo nível de língua(gem).

Pode-se dizer, então, que a tese de Flávia Marinho Lisbôa traz importantes reflexões e contribuições para os estudos discursivos foucaultianos, na medida em que materializa os empecilhos e as problemáticas envolvidas no acesso e na permanência, não somente de alunos indígenas do povo Gavião na Universidade Federal do Sul e Sudeste do Pará (Unifesspa), mas também de outros povos indígenas em diferentes contextos acadêmicos brasileiros. 
Marcus Vinícius Da Silva. Resenha de "Língua como linha de força do dispositivo colonial: os Gavião entre a aldeia e a universidade".

Vale ressaltar, ainda, que o dispositivo colonial trazido na tese da autora nos leva a refletir sobre a memória discursiva do processo de colonização do Brasil, especialmente no que tange a imposição do ensino de língua portuguesa para os povos indígenas no Brasil que, embora pareça um passado distante relacionado a políticas linguísticas autoritárias, continua, ainda, sendo praticada até os dias de hoje nos espaços de saber e poder do âmbito universitário. No entanto, essas políticas carecem de reformulação e mudanças, para que possamos, de fato, garantir o acesso e a permanência de alunos indígenas nas universidades brasileiras e, consequentemente, para que possamos materializar o papel da universidade enquanto espaço plural e heterogêneo de constituição de saberes.

\section{Referências}

BOURDIEU, Pierre. A economia das trocas simbólicas. São Paulo: Perspectiva, 2011.

LISBÔA, Flávia Marinho. Língua como linha de força do dispositivo colonial: os Gavião entre a aldeia e a universidade. 276f. 2019. Tese (Doutorado) - Programa de PósGraduação em Letras, Instituto de Letras e Comunicação, Universidade Federal do Pará, Belém, 2019.

MIGNOLO, Walter. Histórias Locais / Projetos Globais: Colonialidade, Saberes Subalternos e Pensamento Liminar. Belo Horizonte: UFMG, 2003.

NEVES, Ivânia. Patrimônio Cultural Tembé-Tenetehara: terra indígena alto rio Guamá. Belém: Iphan-PA, 2015.

OLIVEIRA, Roberto Cardoso de. Identidade étnica, identificação e manipulação. Sociedade e Cultura, v. 6, n. 2, p. 117-131, 2003.

SANTOS, Boaventura de Sousa; ALMEIDA FILHO, Naomar de. A Universidade no Século XXI: para uma Universidade Nova. Coimbra, 2008.

SANTOS, Lúcia dos. A evasão indígena no Ensino Superior: um estudo do caso do povo Gavião da Terra Indígena Mãe Maria. 88f. 2016. Dissertação (Mestrado em Ciências da Educação) - Escola Superior de Educação Almeida Garrett, Lisboa, 2016.

TESCARI NETO, Aquiles. Resenha de GUERRA, Alessandra Regina. "Diacronia do grau de transparência do sistema de referência por expressão pronominal e desinencial do argumentosujeito de 1a e 2a pessoas no português brasileiro". Tese (Doutorado em Estudos Linguísticos) - UNESP, São José do Rio Preto, 2017, 170p. Revista Letras Escreve, Macapá, v. 9, n. 3, p. 107-112, $2^{\circ}$ sem. 2019.

Recebido em: 15 de janeiro de 2021

Aceito em: 11 de março de 2021 